\title{
Choosing a negative pressure ventilation pump: are there any important differences?
}

\author{
I.E. Smith, M.A. King, J.M. Shneerson
}

Choosing a negative pressure ventilation pump: are there any important differences? I.E. Smith, M.A. King, J.M. Shneerson. CERS Journals 1995.

ABSTRACT: Five negative pressure ventilator pumps were assessed to determine whether there were any differences in performance which were likely to be of clinical importance.

The pumps tested were the NEV-100 (Lifecare Inc.), the Negavent Respirator DA-1 (Dima Italia), the Thompson Maxivent (Puritan Bennett), the CCP-001 and Newmarket pumps (Si-Plan Electronics Research Ltd). A patient model was employed to investigate the relationship between the pressure waveform of each pump and the tidal volume generated, the stability of performance on a continuous $8 \mathrm{~h}$ test, and the response to a change in leak.

On the continuous tests, the stability was better than $\pm 1 \%$ for the inspiratory/expiratory (I:E) ratio and rate, and better than $\pm 10 \%$ for the peak negative pressure for all of the pumps. The Negavent and NEV-100 pumps generated a square wave of pressure and for the same peak negative pressure produced a tidal volume up to $30 \%$ greater than the CCP-001 and the Newmarket pumps, which produced a half sine wave. The Maxivent produced an intermediate waveform, with a plateau at peak negative pressure but a curved decay back to atmospheric pressure. It is argued that if the pressure of the pumps producing a half sine wave is made more negative to compensate and produce an equivalent tidal volume, they are more likely to induce upper airway obstruction. The leak compensation of the NEV-100 and Negavent pumps was nearly complete but took several breaths to develop, the CCP-001 and Newmarket pumps had a very rapid compensation but this was less complete, whilst the Maxivent has no mechanism for leak compensation.

From these results, it seems that in patients liable to upper airway obstruction the NEV-100 and Negavent pumps would be advantageous, whilst when rapidly changing leaks impair the efficiency of negative pressure ventilation the CCP-001 and Newmarket pumps would be preferable. The Maxivent pump seems to offer no advantages.

Eur Respir J., 1995, 8, 1792-1795.
Respiratory Support and Sleep Centre, Papworth Hospital, Cambridge, UK.

Correspondence: I.E. Smith

The Respiratory Support and Sleep Centre Papworth Hospital

Papworth Everard

Cambridge CB3 8RE

UK

Keywords: Cuirass pump

home ventilation

negative pressure ventilation

Received: July 261994

Accepted after revision June 71995
Negative pressure ventilation using a cuirass, jacket or "iron lung" is established as a safe and effective form of ventilatory assistance in subjects with neuromuscular or chest wall disease $[1,2]$. It has been used to provide long-term support in the home [3], and when exacerbations of chronic bronchitis produce respiratory failure [4]. Nasal intermittent positive pressure ventilation via a mask has increasingly replaced negative pressure ventilation, but in our experience there remains a group of patients who cannot tolerate a nasal mask. For these patients, negative pressure ventilation may be the only alternative to tracheostomy ventilation.

There is a range of negative pressure pumps currently available, but to our knowledge there has been no published work comparing their performance. The technical literature provided by the manufacturers does not give all the information required to make clinically important decisions on their use. We therefore examined five negative pressure pumps on a patient model, comparing the influence of the different pressure waveforms on tidal volume, their stability during a prolonged test, and their response to leaks.

\section{Methods}

The five pumps studied were the NEV-100 (Lifecare Inc.), the Negavent Respirator DA-1 (Dima Italia), the Thompson Maxivent (Puritan Bennett), the CCP-001 and Newmarket pumps (Si-Plan Electronics Research Ltd). The physical characteristics, the range of the primary variables of ventilation, and the provision of alarms were measured and recorded. The maximum flow was measured on open circuit through a pneumotachograph, (PK 


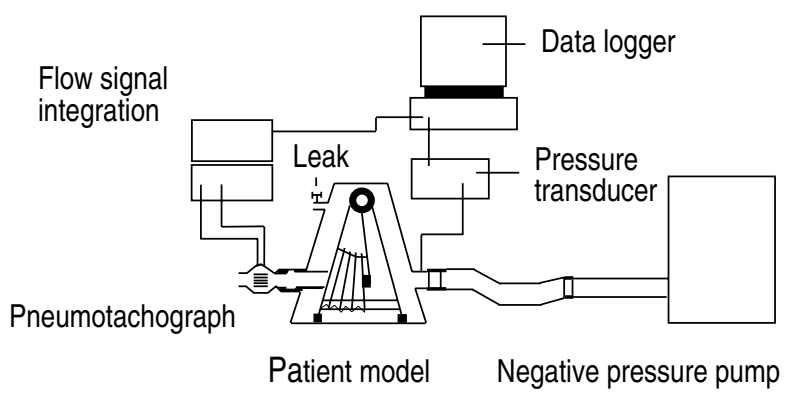

Fig. 1. - Experimental set up for the evaluation of negative pressure pumps.

Morgan), and the maximum negative, and where applicable positive, pressure generated was measured using a calibrated pressure transducer (Si-Plan Electronic Research) with the pump dead-headed. The CCP-001 and Newmarket pumps can be reprogrammed to give different pressure waveforms. In practice, this is rarely done and we tested them as provided by the manufacturer without modification.

Dynamic performance was tested using a lung simulator (Ohmeda) placed within a box with a variable leak to which the pumps were connected using a standard hose $3 \mathrm{~cm}$ in diameter and $225 \mathrm{~cm}$ long (fig. 1). Pressure within the hose was measured at its insertion to the box using a calibrated pressure transducer. Flow into the lung simulator was measured using a pneumotachograph and the signal was integrated (PK Morgan) to give the tidal volume. The signals were sampled at $100 \mathrm{~Hz}$ and recorded on a computer-based data logging system (Archimedes). Selected records were saved as hard copies on a plotter. Initial trials showed that changes in the impedance of the lung simulator affected the tidal volume produced in a predictable fashion, which was not influenced independently by the different pumps. The resistance of the lung simulator was, therefore, set to 5 $\mathrm{cmH}_{2} \mathrm{O} \cdot \mathrm{L}^{-1} \cdot \mathrm{sec}$ and the elastance at $1 \mathrm{~L}$ was set to 50 $\mathrm{cmH}_{2} \mathrm{O} \cdot \mathrm{L}^{-1}$, which gave the greatest range of tidal volumes within the limits of the model.

The accuracy of the primary variables of ventilation was not measured as the controls of the Maxivent, CCP001 and Newmarket pumps are continuous, turning potentiometers. The accuracy of such controls is too operatordependent to be meaningfully assessed. The precision of the rate, the inspiratory/expiratory ratio, and the pressure output were recorded during continuous $8 \mathrm{~h}$ tests. Each pump was initially set at a rate of 15 breaths $\cdot \mathrm{min}^{-1}$, $\mathrm{I}: \mathrm{E}$ ratio of 1:2 (Maxivent 1:1.2), and a pressure of $-30 \mathrm{cmH}_{2} \mathrm{O}$, all confirmed on the patient model. At the start of each test, the pressure waveforms and tidal volumes of 10 consecutive breaths were recorded and averaged. Subsequently, every fiftieth breath was sampled, and the values of pressure and timing recorded and averaged.

The response to a leak was assessed at a range of negative pressures, with the rate again set at 15 breaths $\cdot$ min $^{-1}$ and I:E ratio 1:2. The baseline leak into the box containing the lung simulator was approximately $60 \mathrm{~L} \cdot \mathrm{min}^{-1}$ at a constant pressure of $-30 \mathrm{cmH}_{2} \mathrm{O}$. During the expiratory phase of a breath, an aperture in the side of the box with a cross-sectional area of approximately 380 $\mathrm{mm}^{2}$ was opened. At a constant pressure of $-30 \mathrm{~cm} \mathrm{H}_{2} \mathrm{O}$, this increased the total leak to $400 \mathrm{~L} \cdot \mathrm{min}^{-1}$. After 10 breaths, the tidal volume of the next 10 breaths was recorded and the leak closed again during the expiratory phase.

\section{Results}

The CCP-001 is more compact than the other pumps and is built into a standard briefcase which makes it easy to carry and transport. The Newmarket pump is considerably heavier than the other pumps and few patients would be able, for example, to load it into a car unaided. The range of primary controls of ventilation are given in table 1. Of particular note is the fixed I:E ratio of the Maxivent. The performance on the continuous tests revealed that the I:E ratio and the breath frequency were accurate to within $1 \%$ for all five pumps. There was greater variability of the peak negative pressure. The NEV-100 was the most accurate, with a range of -31.2 to $-29.8 \mathrm{cmH}_{2} \mathrm{O}$ ( $\mathrm{SD} 0.19 \mathrm{cmH}_{2} \mathrm{O}$ ); and the Maxivent was least accurate with a range of -32.8 to $-29.7 \mathrm{cmH}_{2} \mathrm{O}$ (SD $0.4 \mathrm{cmH}_{2} \mathrm{O}$ ).

The pressure outputs of the NEV-100 and the Negavent were very similar and approximated to a square wave. On our patient model with the preset pressure at -30 $\mathrm{cmH}_{2} \mathrm{O}$ and an inspiratory time of $1.33 \mathrm{~s}$ the time taken

Table 1. - The ranges of the primary variables of ventilation, the maximum flow rate and the weight of the five negative pressure pumps

\begin{tabular}{|c|c|c|c|c|c|}
\hline Variable & NEV-100 & Negavent & Maxivent & Newmarket & CCP-001 \\
\hline Breath rate breaths $\cdot \min ^{-1}$ & $4-60$ & $1-50$ & $5.6-25$ & $6-30$ & $10-30$ \\
\hline \multirow[t]{2}{*}{$\mathrm{I}: \mathrm{E}$ ratio } & $1: 29$ & $1: 99$ & $1: 1.2$ & $1: 1.5$ & $1: 1.5$ \\
\hline & to $1: 0.6$ & to $1: 0.2$ & (fixed) & to $1: 0.67$ & to $1: 0.67$ \\
\hline $\begin{array}{c}\text { Maximum negative } \\
\text { pressure } \mathrm{cmH}_{2} \mathrm{O}\end{array}$ & -94 & -89 & -74 & -49 & -38 \\
\hline $\begin{array}{l}\text { Maximum positive } \\
\text { pressure } \mathrm{cmH}_{2} \mathrm{O}\end{array}$ & 30 & N/A & 70 & 51 & 41 \\
\hline Maximum flow $\mathrm{L} \cdot \mathrm{min}^{-1}$ & 845 & 944 & 630 & 780 & 660 \\
\hline Weight kg & 14.5 & 14.5 & 16.5 & 34.8 & 14.7 \\
\hline
\end{tabular}

N/A: not applicable; I:E inspiratory/expiratory ratio. 


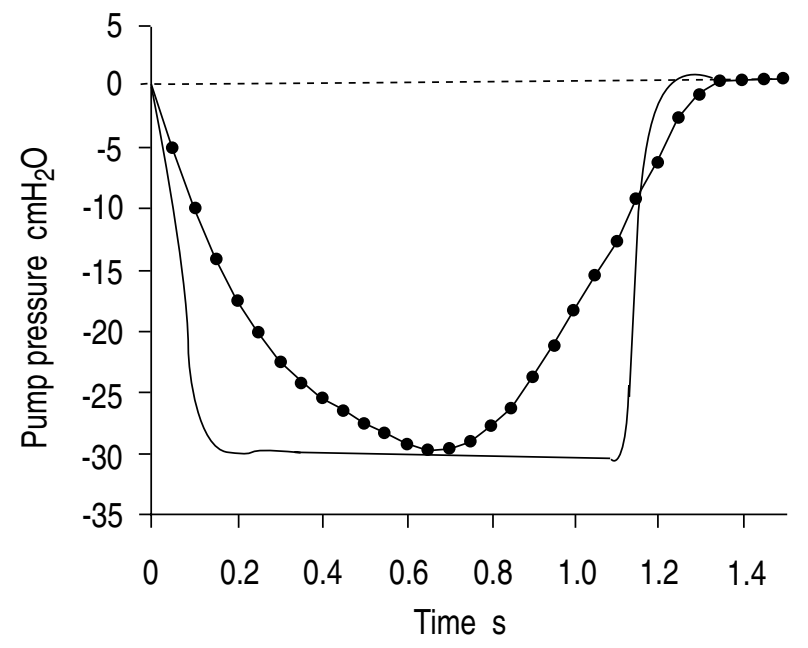

Fig. 2. - Pressure waveforms measured within the patient model, rate 15 breaths $\cdot \mathrm{min}^{-1}$, (I:E) 1:2, preset pressure $-30 \mathrm{cmH}_{2} \mathrm{O}$. — $\mathrm{NEV}$ $100 ; \longrightarrow-$ : Newmarket pump.

to reach $90 \%$ of the peak negative pressure was approximately $125 \mathrm{~ms}$ and the time to $100 \%$ was $200 \mathrm{~ms}$. There was then a plateau and an equally rapid drop in pressure. The pressure output of the CCP-001 and Newmarket pumps, as programmed by the manufacturer, approximated to a half sine wave. For the CCP-001 the time to $90 \%$ of peak negative pressure was $475 \mathrm{~ms}$ and to $100 \%$ was $680 \mathrm{~ms}$. There was no plateau but a curved decay back to atmospheric pressure. The inspiratory time is, therefore, in effect approximately half of that stated on the I:E control, with the second half of the inspiratory phase representing braked expiration.

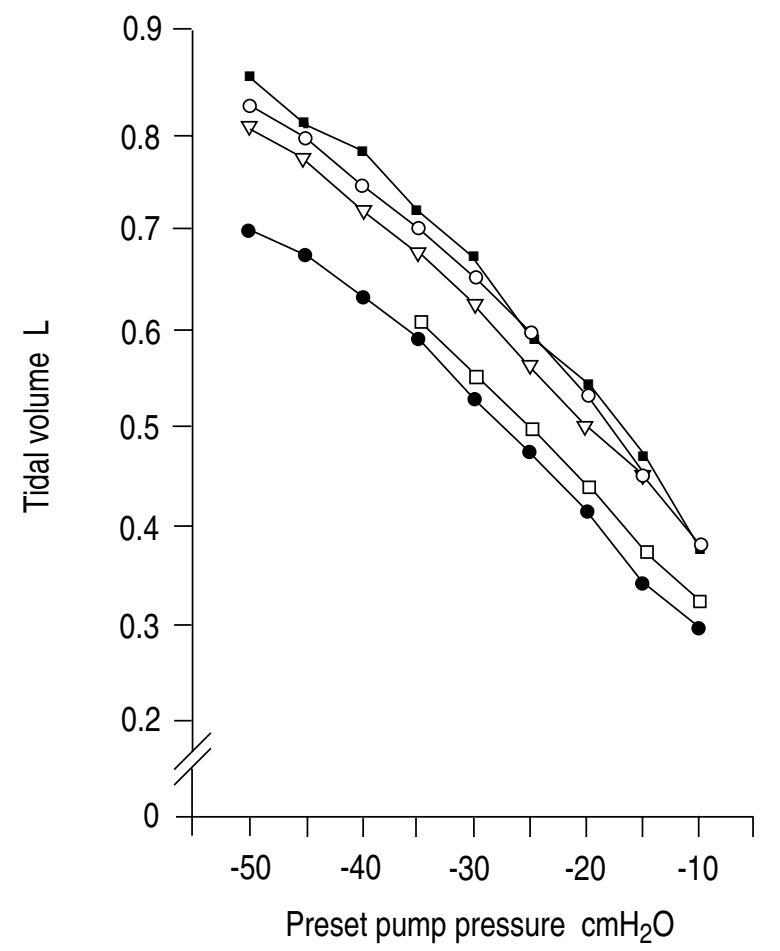

Fig. 3. - Tidal volume produced by the five negative pressure pumps against preset pressure. - - $-\mathrm{NEV}-100 ;-\mathrm{O}-$ : Negavent; $\boldsymbol{\nabla}$-: Maxivent; —- - CCP-001; ——: Newmarket.

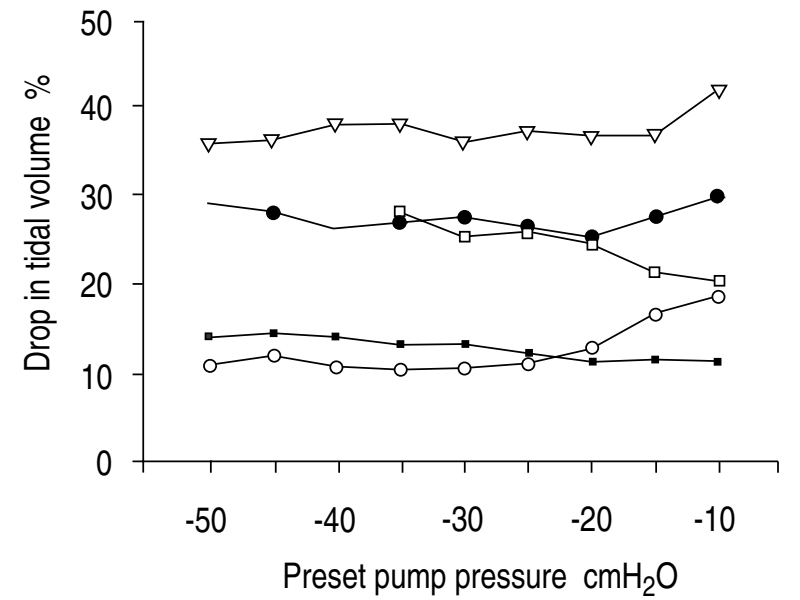

Fig. 4. - The percentage drop in tidal volume when the leak (measured at a constant pressure of $-30 \mathrm{cmH}_{2} \mathrm{O}$ ) in the patient model was increased from 60 to $400 \mathrm{~L} \cdot \mathrm{min}^{-1}$. ——:NEV-100; — - - Negavent; $\boldsymbol{\nabla}$ : Maxivent; —- - CCP-001; ——: Newmarket.

The pressure waveforms of the NEV-100 and Newmarket pumps are reproduced in figure 2. The waveform of pressure generated by the Maxivent is somewhere between the two, with a plateau at peak negative pressure and a sloped decay back to atmospheric pressure. The different waveforms resulted in different tidal volumes for the same preset peak negative pressure (fig. 3). It can be seen that the square waveforms produced the largest tidal volumes and the half sine waveforms the smallest.

The response to leaks was also different for the different pumps (fig. 4). The Maxivent has no mechanism for compensation, and the fall in tidal volume when the leak was increased was proportional to the preset peak negative pressure. The Newmarket pump and the CCP001 have a servo-controlled rotary valve, which adjusts the pressure within the hose continuously with a response time of approximately $25 \mathrm{~ms}$. The response to leaks was rapid but was incomplete. In contrast, the NEV-100 and the Negavent compensate for leaks by increasing the motor speed. This took up to five breaths to develop but was much closer to being complete with the final pressure being within $10 \%$ of the pressure with the baseline leak. When the leak was reduced to the baseline, the Newmarket and the CCP-001 pumps had no tendency to overshoot. Both the NEV-100 and the Negavent produced excessive negative pressures which set off an alarm and disabled the pump.

\section{Discussion}

The ideal pump for negative pressure ventilation would fulfil certain criteria. It would offer a range of rates, I:E ratios and pressures to suit all types of potential patients. The fixed I:E ratio of the Maxivent makes it less flexible than the other pumps and may be inappropriate for patients with airflow limitation and a prolonged expiratory time. The range of negative pressure produced by the CCP-001 was limited compared to the other pumps, and the Negavent does not produce positive pressure. KINNEAR et al. [5] have shown, however, that few patients can tolerate a peak pressure more negative than 
$-40 \mathrm{cmH}_{2} \mathrm{O}$ and that positive pressure offers little benefit. In the absence of a changing leak, the stability of both time and pressure settings was good for all five pumps.

There should be, as a minimum, clearly audible alarms of suitable duration for low pressure/disconnection and power failure, and the latter should have an independent power source. The pumps met these minimum requirements except for the Negavent. The power failure alarm on the Negavent could not be heard in another room and has a duration of only $1 \mathrm{~s}$, which is potentially dangerous.

The pump should respond rapidly within each breath to changing leaks to maintain the preset pressure. All of the patient interfaces for negative pressure ventilation are subject to leaks which are liable to alter with changes in position of the patient [5]. The Maxivent does not provide any leak compensation and, in this respect, is similar to the older Cape cuirass pump, which has been shown to produce a variable pressure at the patient interface and unpredictable ventilation [6]. The CCP-001 and Newmarket pumps offer a rapid but incomplete compensation. The slower pressure compensation of the Negavent and the NEV-100 was more complete but could be disadvantageous in the face of rapidly changing leaks, particularly if the excessive negative pressure condition was reached and the pump was disabled.

One of the greatest limitations of negative pressure ventilation is its tendency to induce obstructive apnoeas due to upper airway collapse. This has been documented in subjects with obstructive airways disease [7], and has been shown to produce symptoms of the sleep apnoea syndrome and suboptimal ventilatory support in patients with neuromuscular disease [8]. The pressure waveform of the ideal pump should be configured to maximize tidal volume, whilst minimizing the risk of inducing upper airway collapse and consequent obstructive apnoeas.

The upper airway behaves as a Starling resistor $[9,10]$, with a collapsible segment most commonly in the pharynx between the relatively rigid nasal airway and trachea. Collapse of this segment depends on the balance between the action of the pharyngeal dilators, in particular genioglossus, and the negative pressure within the lumen. During sleep, when negative pressure ventilation is most commonly employed, the electrical response of genioglossus to a negative pressure within the airway is diminished or absent $[11,12]$. Thus, the most important factor influencing airway patency is the intraluminal pressure, which depends on the negative pressure applied by the pump. The peak negative pressure required to produce a given tidal volume is less negative with a square wave than a sine wave. This indicates that upper airway obstruction would be less likely with the NEV100 and with the Negavent, which produce a square waveform, than the other pumps.

These results show that there are differences between the five negative pressure pumps which have been studied, and that these probably have important clinical consequences. The CCP-001 and Newmarket pumps produce a half sine waveform of negative pressure and are more likely to induce upper airway obstruction than the NEV-100 and Negavent, which produce a square waveform. The slow response to leaks of the latter two pumps makes them less suitable if rapidly changing leaks are present, in which case the rapid compensation of the CCP-001 and the Newmarket pumps is advantageous. The Maxivent, which does not generate a square waveform, has a fixed I:E ratio and has no mechanism for leak compensation, seems to offer no advantages over the other pumps. The peak negative pressure, rate and $\mathrm{I}: \mathrm{E}$ ratio, as provided by the manufacturers, give an incomplete description of the output of these pumps. This should be borne in mind, especially when transferring a patient from one pump to another, when confronted with a patient liable to upper airway obstruction, or when rapidly changing leaks impair the effectiveness of negative pressure ventilation.

\section{References}

1. Curran FJ, Colbert AP. Ventilator management in Duchenne muscular dystrophy and post-poliomyelitis syndrome; twelve years' experience. Arch Phys Med Rehabil 1989; 70: 180-185.

2. Driver AG, Blackburn BB, Marcuard SP, Austin EH. Bilateral diaphragm paralysis treated with cuirass ventilation. Chest 1987; 92: 683-685.

3. Kinnear WJ, Hockley S, Harvey J, Shneerson JM. The effects of one year of nocturnal cuirass-assisted ventilation in chest wall disease. Eur Respir J 1988; 1: 204208.

4. Montserrat JM, Martos JA, Alarcon A, Celis R, Plaza V, Picado $C$. The effect of negative pressure ventilation on arterial blood gas pressures and inspiratory muscle strength during an exacerbation of chronic obstructive lung disease. Thorax 1991; 46: 6-8.

5. Kinnear WJM, Petch M, Taylor G, Shneerson JM. Assisted ventilation using cuirass respirators. Eur Respir J 1988; 1: 198-203.

6. Kinnear WJM, Shneerson JM. The Newmarket pump: a new suction pump for external negative pressure ventilation. Thorax 1985: 40: 677-681.

7. Levy RD, Cosio MG, Gibbons L, Maclem PT, Martin JG. Induction of sleep apnea with negative pressure ventilation in patients with chronic obstructive pulmonary disease. Thorax 1992: 47: 612-615.

8. Bach JR, Penek J. Obstructive sleep apnea complicating negative pressure ventilatory support in patients with chronic paralytic/restrictive ventilatory dysfunction. Chest 1991; 99: 1386-1393.

9. Smith PL, Wise RA, Gold AR, Schwartz AR, Permutt S. Upper airway pressure flow relationships in patients with obstructive sleep apnoea. J Appl Physiol 1988: 64: 789-785.

10. Schwartz AR, Smith PL, Wise RA, Bankman I, Permutt. S. Effect of positive nasal pressure on upper airway pressure-flow relationships. J Appl Physiol 1989; 66(4): $1626-1634$.

11. Wheatley JR, Mezzarotte WS, Tangel DJ, White DP. Influence of sleep on genioglossus muscle activation by negative pressure in normal men. Am Rev Respir Dis 1993; 148: 597-605.

12. Aronson RM, Onal E, Carley DW, Lopata M. Upper airway and respiratory muscle response to continuous negative airway pressure. J Appl Physiol 1989; 66(3): 1373-1382. 